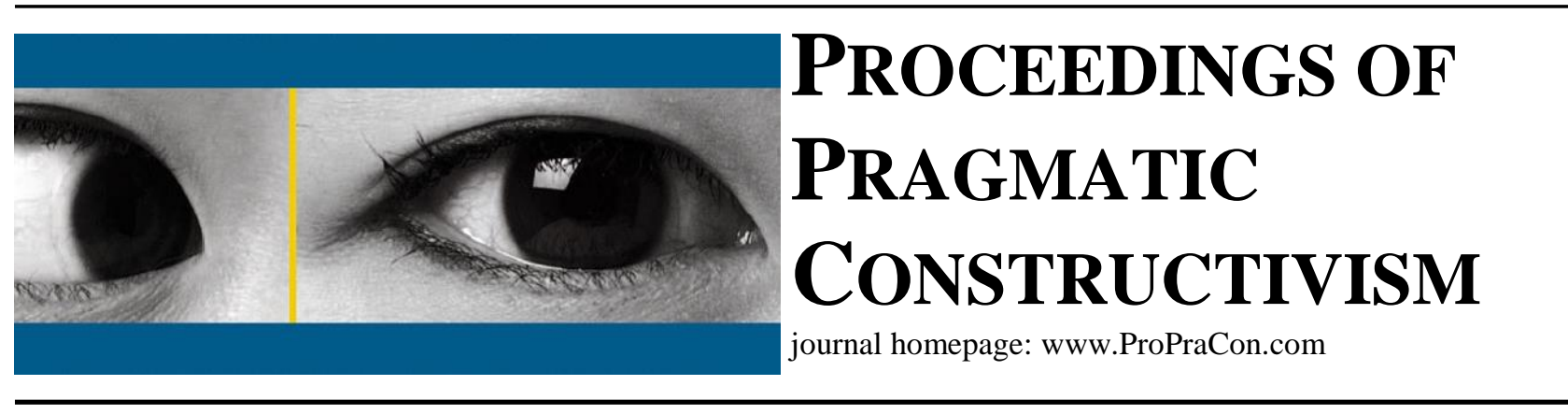

\title{
Editorial: Special Issue on digitalization and the actor's perspective, VIII Actor Reality Construction Conference
}

\author{
Morten Jakobsen, \\ Department of Management, Aarhus University \\ Email:mja@mgmt.au.dk \\ Tuomas Korhonen \\ Cost Management Center at the Tampere University of Technology \\ Email: tuomas.korhonen@tut.fi \\ Teemu Laine, \\ Cost Management Center at the Tampere University of Technology \\ Email: teemu.j.laine@tut.fi
}

\begin{abstract}
About this issue
This issue of Proceedings of Pragmatic Constructivism contains abstracts from the VIII Actor Reality Construction conference held from 24 October to 26 October 2018 at Scuola Superiore Sant 'Anna, Pisa, Italy. The conference was altogether very successful as it presented advancements in Pragmatic Constructivism, and it also connected studies on Pragmatic Constructivism to timely technological developments such as digitalization. The abstracts selected to this issue give indications of topics that that are currently being studied using Pragmatic Constructivism as an analytical framework. As such we are happy share these very early research contributions. Some of these streams of research as well as other contributions under discussion within the Pragmatic Constructivism community will yield full paper publications within this journal in upcoming issues. At the conference, as a practically relevant outcome, formal working groups among the participants of the conference were formed. Five groups will be working actively on the following themes: Costing \& Management Accounting, Values, Language games, Methodology, and Learning. We are looking forward to follow the work from these groups and hopefully be able to publish some of their works through this journal.

The rest of the editorial is organized in the following way. We focus on digitalization as a theme that relates to many interesting research topics of the Pragmatic Constructivism research community. Furthermore, we elaborate on the actor's perspective in the digital era to specify some topics for further research. Finally, we present some conclusions on the conference discussions and avenues for further research in the Proceeding of Pragmatic Constructivism (and elsewhere).
\end{abstract}

\section{On digitalization}

In many of the contributions of this issue, digitalization plays an important role (as well as in the conference). Pragmatic Constructivism can benefit greatly from the work of digitalization researchers - and potentially vice versa. In the conference, we saw presentations that suggested new viewpoints from the digitalization perspective for pragmatic constructivist research. For example, Thomas Bolander, in his keynote speech, presented very insightful points about the distinct characteristics of human vs. machine decision making (see e.g. Bolander, 2018). We could thereby learn new things about digitalization that we could incorporate in our studies of Pragmatic Constructivism. However, the question remains, how can the pragmatic constructivist approach contribute to digitalization and via which channels(?). 
We expect that the new research projects we heard about in the conference and future efforts made in the formed working groups will pave the way for Pragmatic Constructivism in new arenas - digitalization included.

As an example of combining the pragmatic constructivist approach to digitalization and artificial intelligence was provided in the conference by Teemu Laine and Vesa Tiitola, who presented a project (NewBI5), which will examine the possibilities of new technologies in providing the managerial processes with more valuable information. The project will benefit greatly both from the involvement of the international Pragmatic Constructivism community and each of the project's company partner's and their managerial actor's contribution in project activities. Indeed, advancing managerial processes with new technologies requires detailed and in-depth understanding about managerial activities. Besides, it is noteworthy that still managerial actors remain the ones that can be responsible for processes, understand the wider meanings of such processes as well as use their intuition when making decisions. At the same time, it is efficient to take advantage of the intelligence and information processing capabilities in adding value to the data and in supporting some forms of interactions.

Some of the abstracts of this special issue deal with technology development and Pragmatic Constructivism. Trond Bjørnenak and Hanne Nørreklit, in their abstract "Costing vs. prediction machines in pricing decisions A Pragmatic Constructivist approach”, address some questions on digitalization within pricing. They warn that prediction machines might be dangerous, although they can potentially open up new possibilities to approach, e.g. price elasticity at an individual's level. Also, Morten Jakobsen, in his abstract "Cost management and Big Data - searching for possibilities", expects that digitalization will provide some possibilities for accessing future-oriented data in cost management. He also raises some concerns, in this case concerning the usability of Big Data without interpretation. In essence, Jakobsen asks how cost management can embrace Big Data without compromising the traditional cost management criteria.

\section{On actor's perspective in the digital era}

The actor's perspective in the digital era does not only increase the role and use of technologies in management or actor's work. Neither it does mean that research should only focus on digitalization and technologies from this perspective. Instead, also many presentations in the conference encouraged and fostered thinking about the actors themselves and solving the fundamental issues regarding the actors. In this vein Lennart Nørreklit examined the perspective of value in an extensive manner, which is even a more timely issue now when values and responsibilities are sometimes blurred with digitalization. David Kergel, in a similar way, addressed the issue of combining learning and management theories in the era, when learning takes new ways and forms. Hanne Nørreklit, Camilla Kølsen Petersen, Andrea Tenucci and Teemu Laine gave a presentation on the interface of advanced technologies such as artificial intelligence and language games. It is of a great importance to acknowledge the need for applying technologies in a sustainable way, for improving management and managerial work. Indeed, the digital era could help recognize and acknowledge performance in many new ways, but it is up to the managerial actors to drive their behaviour based on their sustainable values.

Again, some remarks from the abstracts of this special issue on very timely issues about the actor's perspective: Camilla Kølsen Petersen, in her abstract "Scripted and live language games in educational reality", makes a distinction between language used in actual teaching of informatics and the respective curriculum tradition. She proposes an analytical framework and uses it to analyse three interviews in the Danish Gymnasium. Michael Paulsen, in his abstract "The good, the bad and the ugly how schools construe digitalization", discusses how the classroom changes after digitalisation arise, and how different response to this arise influence learning. Daniela Ruggeri, Antonio Leotta and Carmela Rizza, in their abstract "Digit accounting as language game for managing organizational spaces," discuss how any language game refers to a specific context, and that digit accounting language game needs to be related to a specific organizational space. They address the question: does digit accounting favour the combination between accounting language games arising from different organizational spaces?

Jakob Liboriussen, Hanne Nørreklit and Mihaela Trenca, in their abstract "Performance Management of Cultural Events - The Case of Aarhus European Capital of Culture 2017”, examine how organization can manage their performance without interfering too much with creativity. In their case, trust among actors forms the basis of an interactive process of monitoring performance, in a reflective manner.

Lennart Nørreklit, in his abstract "The foundation of value”, discusses the problem of defining values in a naturalist and empirical manner. His analysis has implications for examining language games in social practices. In his other abstract, "IT and Paranoiac Rule", Lennart Nørreklit suggests that we do not live in a period of high knowledge but in one of post truth and pathos. He claims that IT systems are risky when they are used to control people because they hinder the use of free language; possibly causing paranoia of understanding everything related to a certain target as 
inherently "bad”. Lennart Nørreklit, Lisa Jack and Hanne Nørreklit, in their abstract "Beyond the Post-Truth Turn: From Habitus Based to Paranoiac Based Performance Management”, examine the problems of measuring university performance. Based on their abstract, determining success from failure is highly problematic. Their case shows that Excel Spreadsheets epitomize digital scripts in performance management.

Stefan Schaper, Marco Giuliani and Maria Serena Chiucchi, in their abstract “The Actor's Role in the Survival of non-financial Management and Reporting Practices: the case of IC reporting in Denmark and Italy”, examine intellectual capital management. They present cases from Denmark and Italy, to better understand the use of intellectual capital statements, and show a demise of intellectual capital reporting practice in both of their cases. Lino Cinquini, Cristina Campanale, Sara Giovanna Mauro and Andrea Tenucci show, in their abstract “(Un)Performing Universities: the contradictory impacts of powerful numbers", how they intent to investigate the results of performance measurement systems in universities. Their research is expected to contribute to the existing body of knowledge about the effect of performance measurement systems in universities and the effect on academics, through the lens of values investigation.

Pinar Guven Uslu, Zlatinka Blaber and Pawan Adhikari, in their abstract "Pragmatic Constructivism and InterOrganisational Decision Making”, study the English National Health Service. They find out that joint authorship among certain boundary spanners is a key element in inter-organizational decision making.

Riccardo Giannetti, Fabio Magnacca and Giovanna Mariani, explore the role and the use of management accounting (MA) within an academic-based new product development research project, which is a temporary organisation whose objective is to transform scientific knowledge into an exploitable innovation.

Finally, Antonio Leotta, Lino Cinquini, Carmela Rizza, Daniela Ruggeri, and Andrea Tenucci discuss digitalization and validity in business planning. They do so through a case of a global retailer. By using the practice of the global retailer company they discuss how planning through digitalisation can assist construction of cohenrece between local and company levels.

\section{Concluding remarks}

The VIII Actor Reality Construction Conference showed several advancements of the community and also the relevance and significance of the pragmatic constructivist research area. This observation is echoed in the remarks of the conference presentations in this editorial and the abstracts published in this special issue. It is up to the Pragmatic Constructivism community to advance the understanding about the actor's perspective, also under the circumstances that challenge different actor's roles within organizations and enable and force rethinking of the actor's perspective in many ways. Such circumstances are likely to emerge when managerial roles meet digitalization (e.g., Brynjolfsson and Mitchell, 2017; Mitchell and Brynjolfsson, 2017). However, these theoretically and philosophically challenging issues have become ultimately timely and relevant for many organizations - and for research respectively (e.g., Quattrone, 2016; Arnaboldi et al., 2017; Gärtner and Hiebl, 2018). Therefore, the interface of Pragmatic Constructivism and digitalization is supposed to yield substantial contribution in the upcoming years.

As the Editors of Proceedings of Pragmatic Constructivism, we can advance the research agenda outlined and elaborated on in the Pisa conference to a certain degree. However, new research books and new teaching methods are needed. The Actor Reality Construction conferences are a suitable arena for discussing these topics. However, we encourage authors to utilize Pragmatic Constructivism in publishing channels (e.g., journals) outside the convenient arenas. Recent experiences suggest that researchers outside the immediate surroundings of Pragmatic Constructivism could be very interested in the approach and, after becoming familiar with it, find new ways to verbalize some of the real-life issues they confront.

\section{References}

Arnaboldi, M., Busco, C., Cuganesan, S., 2017. Accounting, accountability, social media and big data: revolution or hype? Accounting, Auditing \& Accountability Journal, 30, 762-776.

Bolander, T. 2018. Seeing Is Believing: Formalising False-Belief Tasks in Dynamic Epistemic Logic. In: van Ditmarsch H., Sandu G. (Eds.), Jaakko Hintikka on Knowledge and Game-Theoretical Semantics (pp. 207-236). Springer, Cham.

Brynjolfsson, E., Mitchell, T. 2017. What can machine learning do? Workforce implications. Science, 358(6370), 1530-1534.

Gärtner, B., Hiebl, M.R., 2018. Issues with Big Data, In: Quinn, M., Strauss, E. (Eds.), The Routledge

Companion to Accounting Information Systems. Routledge.

Mitchell, T., Brynjolfsson, E. 2017. Track how technology is transforming work. Nature, 544(7650), 290-292.

Quattrone, P., 2016. Management accounting goes digital: Will the move make it wiser? Management

Accounting Research, 31, 118-122. 